Cite this: J. Mater. Chem. A, 2014, 2 , 8246

Received 18th January 2014 Accepted 28th February 2014

DOI: $10.1039 / c 4 t a 00299 \mathrm{~g}$

www.rsc.org/MaterialsA

\title{
Highly hydrogen permselective ZIF-8 membranes supported on polydopamine functionalized macroporous stainless-steel-nets $\dagger$
}

\begin{abstract}
Aisheng Huang, ${ }^{\text {a }}$ Qian Liu, ${ }^{a}$ Nanyi Wang ${ }^{\mathrm{b}}$ and Jürgen Caro ${ }^{\mathrm{b}}$
Inspired by the bio-adhesive ability of the marine mussel, highly hydrogen permselective ZIF- 8 membranes were prepared on polydopamine functionalized stainless-steel-nets (SSNs). With polydopamine functionalization of SSNs under mild conditions, the nucleation and growth of well-intergrown ZIF-8 membranes were promoted through the formation of strong non-covalent and covalent bonds, which was helpful to enhance the membrane's separation selectivity while maintaining high permeance. For binary mixtures at $100{ }^{\circ} \mathrm{C}$ and 1 bar, the mixture separation factors of $\mathrm{H}_{2}-\mathrm{CO}_{2}, \mathrm{H}_{2}-\mathrm{N}_{2}, \mathrm{H}_{2}-\mathrm{CH}_{4}$ and $\mathrm{H}_{2}-\mathrm{C}_{3} \mathrm{H}_{8}$, were found to be 8.1, 15.0, 23.2 and 329.7, which by far exceed the corresponding Knudsen coefficients and those of the as-reported ZIF- 8 membranes. The ZIF- 8 membranes also displayed high permeances, with the $\mathrm{H}_{2}$ permeance higher than $2.1 \times 10^{-5} \mathrm{~mol} \mathrm{~m}^{-2} \mathrm{~s}^{-1} \mathrm{~Pa}^{-1}$ due to the high void volume of the SSNs.
\end{abstract}

\section{Introduction}

Metal-organic frameworks (MOFs) have attracted intense interest for applications in gas adsorption and storage, molecular separation, and catalysis due to their highly diversified structures and pore sizes as well as their specific adsorption affinities..$^{1-5}$ Recently, a great deal of research effort has been focused on the preparation of supported MOF layers for their potential applications as separators, reactors, and sensors. ${ }^{6-12}$ In particular, zeolitic imidazolate frameworks (ZIFs), which consist of transition metals (Zn, Co) and imidazolate linkers, ${ }^{13}$ have emerged as novel porous materials for the fabrication of molecular sieve membranes due to their zeolite-like properties such as permanent porosities, uniform pore sizes, and exceptional thermal and chemical stabilities. ${ }^{12-31}$ So far, ZIF-7, ${ }^{14}$ ZIF$8,{ }^{15-25}$ ZIF-22, ${ }^{26}$ ZIF-69, ${ }^{27}$ ZIF-71,${ }^{28}$ ZIF-90, ${ }^{29-31}$ and ZIF-95 (ref. 32) membranes have successfully been prepared on various ceramic supports for single gas permeation or gas mixture separation.

Among the reported ZIF membranes, SOD ZIF-8 membranes, with high thermal and chemical stabilities as well as small pore apertures $(\sim 0.34 \mathrm{~nm}),{ }^{13}$ have been widely studied

${ }^{a}$ Institute of New Energy Technology, Ningbo Institute of Material Technology and Engineering, CAS, 519 Zhuangshi Road, 315201 Ningbo, P. R. China. E-mail: huangaisheng@nimte.ac.cn

${ }^{b}$ Institute of Physical Chemistry and Electrochemistry Leibniz University Hannover, Callinstraße 3-3A, D-30167 Hannover, Germany

$\dagger$ Electronic supplementary information (ESI) available: Experimental details, photographs, SEM images and XRD data of the ZIF-8 membranes, and separation performances. See DOI: 10.1039/c4ta00299g and are of special interest for the fabrication of molecular sieve membranes. In the last five years, more and more effort has been paid to the preparation of ZIF-8 membranes by in situ growth, secondary growth, and also the liquid phase epitaxy method. ${ }^{16-25,33}$ However, it was often found that separate ZIF-8 crystals or islands rather than continuous layers were formed on the native ceramic supports by direct solvothermal synthetic routes because heterogeneous nucleation of ZIF-8 crystals on the support surfaces was very poor. ${ }^{17,26}$ Therefore, seed coating ${ }^{20,21}$ or chemical modification ${ }^{17,26}$ of the supports have been applied to promote the heterogeneous nucleation of ZIF-8 crystals on support surfaces. Recently, inspired by the bio-adhesive ability of the marine mussel, we developed a simple, versatile and powerful synthetic strategy to prepare highly reproducible and selective ZIF-8 membranes without seeding by using polydopamine (PDA) as a novel covalent linker. ${ }^{34}$

It should be noted that, in previous reports, the ZIF-8 membranes were usually prepared on porous oxide ceramics such as $\mathrm{TiO}_{2}$ or $\mathrm{Al}_{2} \mathrm{O}_{3}$ disks. These ZIF-8 membranes have shown promising separation selectivities, but the hydrogen permeances were relatively low for practical applications due to the large flow resistance for gas transport through the thick ceramic supports (usual thickness 1 to $2 \mathrm{~mm}$ ). In order to increase the permeance, Yao et al. prepared a highly permeable ZIF-8 membrane on a flexible nylon substrate using a contradiffusion synthetic method. ${ }^{22}$ However, the $\mathrm{H}_{2}-\mathrm{N}_{2}$ ideal selectivity of the ZIF-8 membrane is 3.7 , indicating that there were non-negligible defects. Therefore, the challenge is to prepare ZIF-8 membranes with high permeance, while maintaining their high separation selectivity. 
In the present work, we report a highly hydrogen permselective ZIF-8 membrane supported on a macroporous stainlesssteel-net (SSN). The thread woven for the SSN is about $25 \mu \mathrm{m}$ thick, and the aperture of the SSN is about $30 \times 30 \mu \mathrm{m}$ in diameter. Therefore, the SSN has the same thickness as the thread diameter, which is much thinner - and thus has a higher void volume - than a conventional $\alpha-\mathrm{Al}_{2} \mathrm{O}_{3}$ support. As reported previously, ${ }^{35}$ zeolite LTA membranes supported on SSNs can show higher permeances. Therefore, it can be expected that the ZIF-8 membranes supported on SSNs will show much higher permeances. However, to the best of our knowledge, there are no reports on the preparation of ZIF-8 membranes on SSNs.

Since there are fewer surface hydroxy groups on SSN surfaces to form covalent bonds with the ZIF-8 frameworks, the heterogeneous nucleation of ZIF-8 on SSN surfaces is very poor. In order to promote the nucleation and growth of well-intergrown ZIF-8 layers on the SSNs, the SSNs were functionalized with PDA before synthesis (Fig. 1). Attributed to its adhesive ability through the formation of strong non-covalent and covalent bonds, ${ }^{36,37}$ the PDA is expected to promote the nucleation and growth of well-intergrown ZIF-8 membranes.

\section{Experimental}

Materials

Chemicals were used as received: zinc chloride ( $>99 \%$, Merck), 2-methylimidazole ( $>99 \%$, Aladdin), sodium formate $(>99 \%$, Aladdin), dopamine (DPA, 98\%, Aladdin), tris(hydroxymethyl) aminomethane hydrochloride (Tris-HCl, 99\%, Aladdin), methanol (99.9\%, Aladdin). The stainless-steel-nets (SSNs, 500 mesh, 316L, Yingkaimo stainless-steel-net Co., Hebei, China) were cut as wafers of $18 \mathrm{~mm}$ in diameter and were cleaned with ethanol under ultrasonication for $30 \mathrm{~min}$ before they were used as supports.

\section{Dopamine functionalization of the SSN surfaces}

Dopamine ( $2 \mathrm{mg} \mathrm{mL}^{-1}$ ) was dissolved in $10 \mathrm{mM}$ Tris- $\mathrm{HCl}(\mathrm{pH}$ $8.5)$ in an open watch glass (150 $\mathrm{mm}$ in diameter). Then SSN wafers and $\alpha-\mathrm{Al}_{2} \mathrm{O}_{3}$ disks were treated with dopamine at $25{ }^{\circ} \mathrm{C}$ for $24 \mathrm{~h}$, leading to polydopamine layers being deposited on the support surfaces. ${ }^{34}$

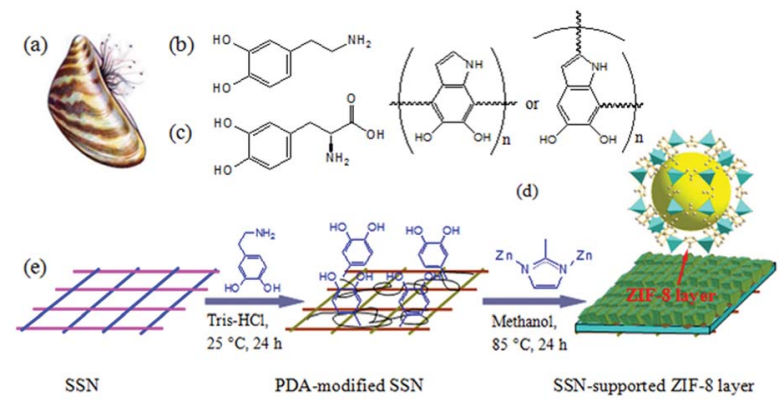

Fig. 1 Mussel with byssus threads (a), chemical structures of DPA (b), DOPA (c), and PDA (d), and a scheme of the preparation of a ZIF-8 molecular sieve membrane on a PDA-functionalized SSN (e).
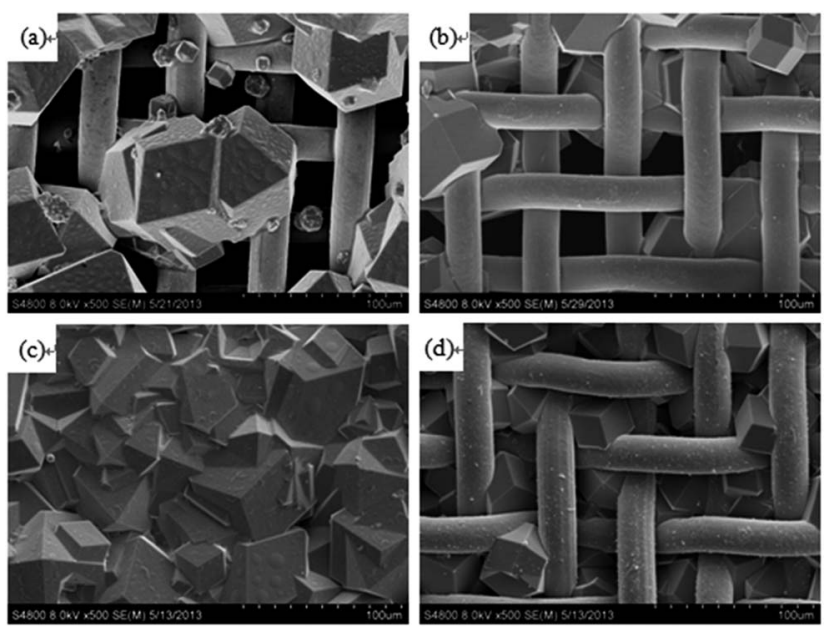

Fig. 2 FESEM images of the upper side (a) and the down side (b) of the ZIF- 8 layer prepared for $24 \mathrm{~h}$ on a non-modified SSN. FESEM images of the upper side (c) and the down side (d) of the of ZIF- 8 membrane prepared for $24 \mathrm{~h}$ on a PDA-functionalized SSN. The attributes "upper" and "down" refer to the horizontal orientation of the SSNs in the ZIF- 8 membrane synthesis.

\section{Synthesis of ZIF-8 membranes on PDA-modified SSN surfaces}

The ZIF-8 membrane was prepared according to the following procedure as reported elsewhere, with minor modifications. ${ }^{16} \mathrm{~A}$ solid mixture of $0.538 \mathrm{~g}$ zinc chloride, $0.648 \mathrm{~g}$ 2-methylimidazole and $0.268 \mathrm{~g}$ sodium formate was dissolved in $50 \mathrm{ml}$ methanol by ultrasonic treatment. PDA-treated or PDA-free supports were placed horizontally in a Teflon-lined stainless steel autoclave which was filled with the synthesis solution, and heated to $85{ }^{\circ} \mathrm{C}$ in an air oven for $24 \mathrm{~h}$.

\section{Characterization of the ZIF-8 membranes}

The morphology of the ZIF-8 membranes was investigated by field emission scanning electron microscopy (FESEM). FESEM

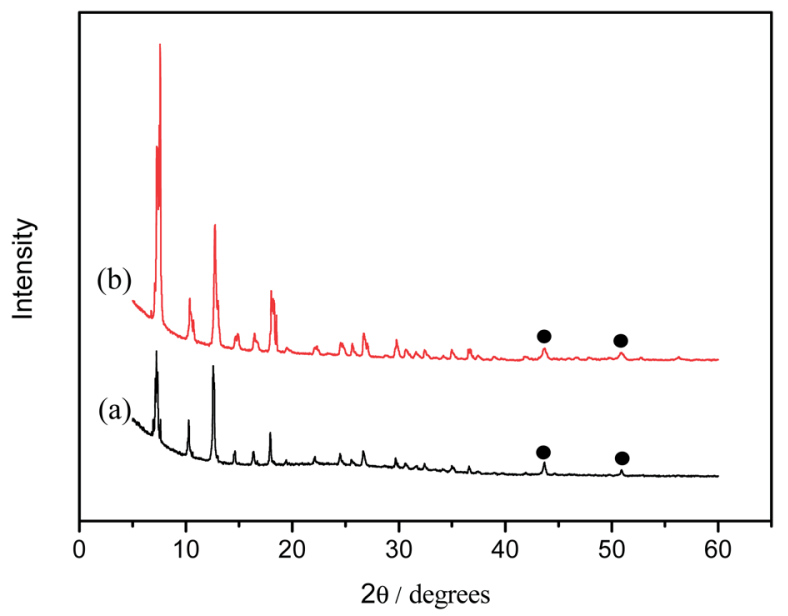

Fig. 3 XRD patterns of the ZIF-8 layers prepared on a non-modified SSN (a), and a PDA-functionalized SSN (b). ( ) : SSN. Not marked: ZIF8 crystals. 

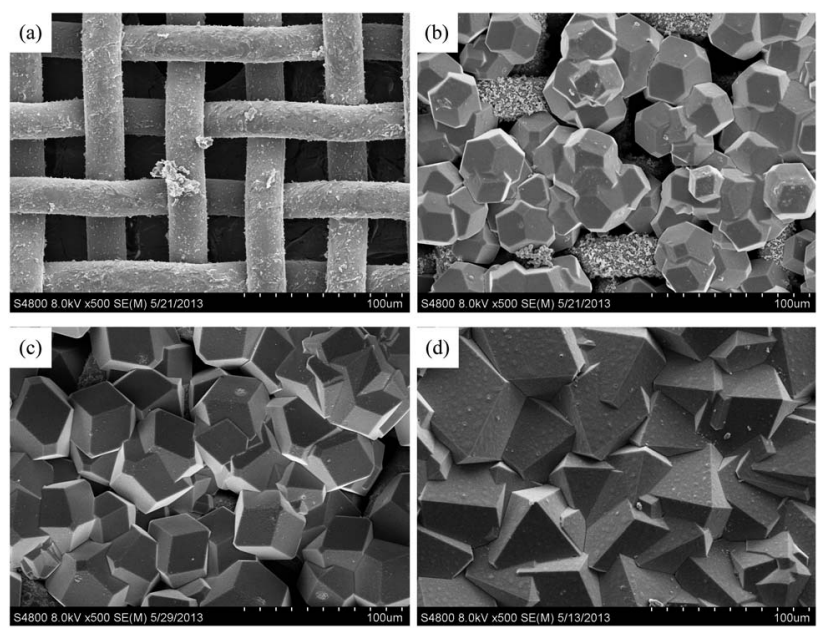

Fig. 4 FESEM images of ZIF- 8 layers prepared on DPA-functionalized SSNs with different synthesis times: $4 \mathrm{~h}$ (a), $8 \mathrm{~h}$ (b), $16 \mathrm{~h}$ (c), and $24 \mathrm{~h}$ (d)

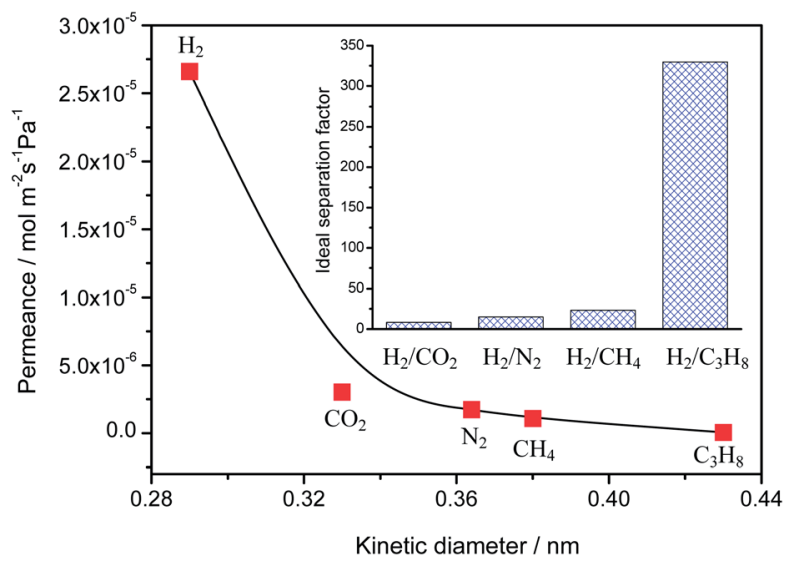

Fig. 5 Single gas permeances on the ZIF-8 membrane prepared on PDA-functionalized SSN at $100^{\circ} \mathrm{C}$ and 1 bar as a function of the kinetic diameter. The inset shows the mixture separation factors for $\mathrm{H}_{2}$ over other gases from equimolar mixtures as determined by gas chromatography.

micrographs were taken on an S-4800 (Hitachi) with a cold field emission gun operating at $4 \mathrm{kV}$ and $10 \mu \mathrm{A}$. The phase purity and crystallinity of the ZIF-8 membranes were confirmed by X-ray

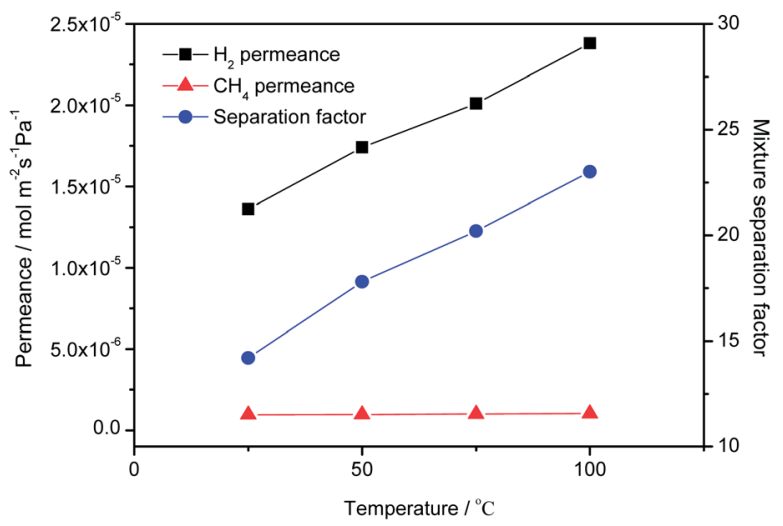

Fig. 6 Gas permeances and $\mathrm{H}_{2}-\mathrm{CH}_{4}$ selectivity of a ZIF- 8 membrane supported on a PDA-functionalized SSN as a function of temperature at 1 bar.

diffraction (XRD). The XRD patterns were recorded at room temperature under ambient conditions with a Bruker D8 ADVANCE X-ray diffractometer with CuKa radiation at $40 \mathrm{kV}$ and $40 \mathrm{~mA}$.

\section{Single gas permeation and mixed gases separation}

For the single gas permeation and mixed gases separation, the supported ZIF-8 membrane was sealed in a permeation module with silicone O-rings. The feed gases were fed to the top-side of the membrane, and the sweep gas was fed on the permeate side to keep the concentration of permeating gas low, providing a driving force for permeation. The total pressure on each side of the membrane was atmospheric. For both single and gas mixture permeation, the fluxes of feed and sweep gases were determined with mass flow controllers, and a calibrated gas chromatograph (Echrom A90) was used to measure the gas concentrations, as shown elsewhere. ${ }^{26}$ The separation factor $\alpha_{\mathrm{i}, \mathrm{j}}$ of a binary mixture permeation is defined as the quotient of the molar ratios of the components ( $i$ and $j$ ) in the permeate, divided by the quotient of the molar ratio of the components ( $\mathrm{i}$ and $\mathrm{j}$ ) in the retentate, as shown in following.

$$
\alpha_{\mathrm{i} / \mathrm{j}}=\frac{y_{\mathrm{i}, \text { Perm }} / y_{\mathrm{j}, \text { Perm }}}{y_{\mathrm{i}, \text { Ret }} / y_{\mathrm{j}, \text { Ret }}}
$$

Table 1 Comparison of the gas separation performances of ZIF-8 membranes prepared on difference supports

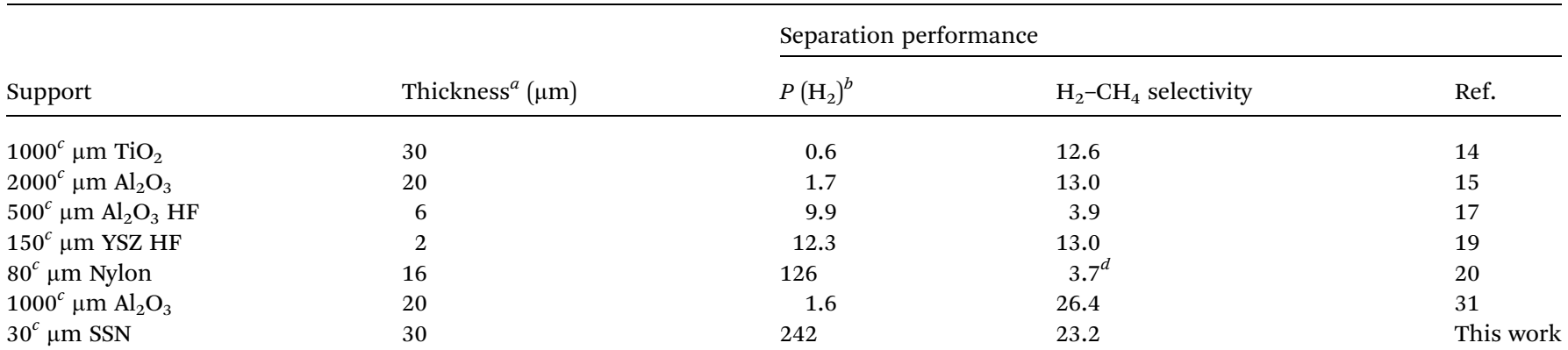

${ }^{a}$ Membranes thickness. ${ }^{b} \mathrm{H}_{2}$ permeance $\left(\times 10^{-7} \mathrm{~mol} \mathrm{~m}{ }^{-2} \mathrm{~s}^{-1} \mathrm{~Pa}^{-1}\right) .{ }^{c}$ Support thickness. ${ }^{d} \mathrm{H}_{2}-\mathrm{N}_{2}$ selectivity. 


\section{Results and discussion}

By simple immersion of the SSN supports in a buffered aqueous solution of DPA $(\mathrm{pH}=8.5)$ at room temperature for $24 \mathrm{~h}$, the DPA polymerized to PDA and was readily deposited on the SSN support (Fig. S1b †). Then the ZIF-8 membranes were prepared on the PDA-functionalized SSNs at $85{ }^{\circ} \mathrm{C}$ for $24 \mathrm{~h}$. In good agreement with our previous report, ${ }^{34}$ it was difficult to direct heterogeneous nucleation and growth of a continuous ZIF-8 layer on the non-modified SSN surface (Fig. 2a and b), and tremendous pinholes were easily observed since there are no additional linkage groups in ZIF-8 frameworks to form covalent bonds with the surface OH groups of the SSN supports.

Whereas, after modification of the SSN with PDA before the solvothermal reaction, a dense ZIF-8 layer was easily formed on the PDA-functionalized SSN. As shown in Fig. 2c, the upper side of the horizontally oriented SSN surface is completely covered with well intergrown rhombic dodecahedron crystals, and no visible cracks, pinholes or other defects are observed. In the present work, both the amino-groups and the hydroxyl aminogroups of PDA can coordinate to the free $\mathrm{Zn}^{2+}$ centers and bind to the growing nano-crystals directly. Therefore, covalent bonds (Zn-N and $\mathrm{Zn}-\mathrm{O})$ between the growing ZIF-8 layer and the support were formed to anchor the ZIF-8 crystals for membrane formation. ${ }^{26}$ The formation of a dense ZIF-8 layer is also confirmed by the down side image of the ZIF- 8 membrane. It can be seen that ZIF- 8 crystals with comparable sizes of about 40 $\mu \mathrm{m}$ were grown in the meshes of the SSN and closed it completely (Fig. 2d). Interestingly, the SSN acts as a framework for the formation of a dense ZIF-8 membrane, just like the steel bars used to reinforce concrete in building construction. Such a "reinforced concrete" structure can increase the mechanical stability of the ZIF-8 membrane layer sticking to the support surface. Indeed, as shown in Fig. S2, $\uparrow$ the membrane morphology remains unchanged after $10 \mathrm{~min}$ of ultrasonic treatment in ethanol, and no crystal exfoliation or detachment from the membrane layer was observed.

Fig. 3 shows the XRD patterns of the ZIF-8 layers prepared on non-modified and PDA-functionalized SSNs. It can be seen that all of the peaks of the membrane layer match well with the reported structural data of ZIF-8, as well as the SSN signals, ${ }^{16,34}$ indicating that a phase-pure ZIF-8 membrane with high crystallinity has been formed on the SSN supports. In comparison with the XRD pattern of the ZIF-8 membrane prepared on a nonmodified SSN, the XRD pattern of the ZIF- 8 membrane prepared on a PDA-functionalized SSN exhibits a stronger intensity due to the formation of a denser membrane layer. Fig. 4 shows the FESEM images of the ZIF-8 membranes prepared on PDA-functionalized SSNs at $85{ }^{\circ} \mathrm{C}$ for different synthesis times. As shown in Fig. 4a, only amorphous phases rather than ZIF-8 crystals are observed on the SSN surface after $4 \mathrm{~h}$. Up to a crystallization time of $8 \mathrm{~h}$, ZIF- 8 crystals with clear facets have been formed on the SSN surface, but inter-crystalline gaps are observable between the ZIF-8 crystals (Fig. 4b). With increasing the crystallization time up to $24 \mathrm{~h}$, the ZIF-8 crystals grow together and form a homogeneous and compact ZIF-8 membrane (Fig. 4d). It is worth noting that the PDA functionalization is done under mild conditions (simple immersion in a buffered aqueous solution of DPA at room temperature), in comparison with the previously proposed chemical modification methods, ${ }^{26,29}$ which is helpful for the preparation of ZIF-8 membranes on a large-scale and for reducing the costs of membrane manufacturing. Further, it is found that PDA functionalization also facilitates the formation of dense zeolite LTA membranes on the PDA-functionalized SSNs (Fig. S3†).

The volumetric flow rates of the single gases $\mathrm{H}_{2}, \mathrm{CO}_{2}, \mathrm{~N}_{2}, \mathrm{CH}_{4}$ and $\mathrm{C}_{3} \mathrm{H}_{8}$ as well as the equimolar binary mixtures of $\mathrm{H}_{2}$ with $\mathrm{CO}_{2}, \mathrm{~N}_{2}, \mathrm{CH}_{4}$ and $\mathrm{C}_{3} \mathrm{H}_{8}$ were measured using the Wicke-Kallenbach technique. ${ }^{\mathbf{2 6 , 2 9}}$ The permeances and separation factors are summarized in Table S1. $\dagger$ Fig. 5 shows the permeances of the single gases through the SSN-supported ZIF- 8 membrane as a function of the kinetic diameters of the permeating molecules at $100{ }^{\circ} \mathrm{C}$ and 1 bar. As shown in Fig. 5 and Table $\mathrm{S} 1, \dagger$ the gas permeances clearly depend on molecular size with the order: $\mathrm{H}_{2}$ $>\mathrm{CO}_{2}>\mathrm{N}_{2}>\mathrm{CH}_{4}>\mathrm{C}_{3} \mathrm{H}_{8}$. The $\mathrm{H}_{2}$ permeance of $2.66 \times 10^{-5} \mathrm{~mol}$ $\mathrm{m}^{-2} \mathrm{~s}^{-1} \mathrm{~Pa}^{-1}$ is much higher than that of the other gases due to the small kinetic diameter of hydrogen of $0.29 \mathrm{~nm}$. The ideal separation factors of $\mathrm{H}_{2}$ from $\mathrm{CO}_{2}, \mathrm{~N}_{2}, \mathrm{CH}_{4}$ and $\mathrm{C}_{3} \mathrm{H}_{8}$, determined as the ratio of the single component permeances, are 8.8, 15.4, 24.6 and 442.5 (Table S1 $\dagger$ ), indicating that the ZIF-8 membrane displays high $\mathrm{H}_{2}$ permselectivity.

The molecular sieve performance of the ZIF-8 membrane was confirmed by the separation of equimolar mixtures of $\mathrm{H}_{2}$ and $\mathrm{CO}_{2}, \mathrm{~N}_{2}, \mathrm{CH}_{4}$, and $\mathrm{C}_{3} \mathrm{H}_{8}$ at $100{ }^{\circ} \mathrm{C}$ and 1 bar. As shown in Table $\mathrm{S} 1, \dagger$ compared with the $\mathrm{H}_{2}$ single gas permeance, only a slight reduction of $\mathrm{H}_{2}$ permeance in the mixtures was observed, with a $\mathrm{H}_{2}$ permeance of about 2.12-2.46 $\times 10^{-5} \mathrm{~mol} \mathrm{~m}^{-2} \mathrm{~s}^{-1} \mathrm{~Pa}^{-1}$, suggesting that the larger molecules $\left(\mathrm{CO}_{2}, \mathrm{~N}_{2}, \mathrm{CH}_{4}\right.$, and $\left.\mathrm{C}_{3} \mathrm{H}_{8}\right)$ only slightly hinder the permeation of the highly mobile $\mathrm{H}_{2}$. For the equimolar mixtures, the mixture separation factors of $\mathrm{H}_{2}$ $\mathrm{CO}_{2}, \mathrm{H}_{2}-\mathrm{N}_{2}, \mathrm{H}_{2}-\mathrm{CH}_{4}$ and $\mathrm{H}_{2}-\mathrm{C}_{3} \mathrm{H}_{8}$ were 8.1, 15.0, 23.2 and 329.7 (inset in Fig. 5), which by far exceed the corresponding Knudsen coefficients (4.7, 3.7, 2.8 and 4.7, respectively). Attributed to the amazing adhesive ability of PDA, the PDA modification is helpful for the synthesis of well-intergrown, highly selective and reproducibile ZIF-8 membranes (Table $\mathrm{S} 2 \dagger$ ). The average $\mathrm{H}_{2}-$ $\mathrm{CH}_{4}$ selectivity was $22.5 \pm 0.55$ (standard deviation) for three independent membranes.

We have reported the first continuous ZIF-8 membranes on $\mathrm{TiO}_{2}$ disks by a microwave-assisted solvothermal synthetic method, with a good $\mathrm{H}_{2}-\mathrm{CH}_{4}$ selectivity of 12.6 , but a relatively low hydrogen permeance of $0.6 \times 10^{-7} \mathrm{~mol} \mathrm{~m}^{-2} \mathrm{~s}^{-1} \mathrm{~Pa}^{-1}$ due to the thick membrane layer $(\sim 30 \mu \mathrm{m}) .{ }^{16}$ By reducing the membrane thickness to $20 \mu \mathrm{m}$, Jeong et al. reported a higher permeance for a ZIF-8 membrane $\left(1.7 \times 10^{-7} \mathrm{~mol} \mathrm{~m}^{-2} \mathrm{~s}^{-1} \mathrm{~Pa}^{-1}\right)$ prepared on $\mathrm{Al}_{2} \mathrm{O}_{3}$ disks with a $\mathrm{H}_{2}-\mathrm{CH}_{4}$ selectivity of $13.0 .{ }^{17}$ It should be noted that not only the membrane thickness but also the support materials and their thicknesses have great effects on the permeance (Table 1). Lai and colleagues prepared high permselective ZIF-8 membranes on YSZ (yttria-stabilized zirconia) hollow fibers (HF) through secondary growth with seeding. ${ }^{21}$ Wang and colleagues synthesized a highly permeable ZIF-8 membrane on a flexible nylon polymer using a contra- 
diffusion synthetic method. ${ }^{22}$ However, the $\mathrm{H}_{2}-\mathrm{N}_{2}$ selectivity of the ZIF-8 membrane was only 3.7, indicating that macroporous defects were present in the membrane layer. In the present work, attributed to the formation of strong non-covalent and covalent bonds between the SSN and the ZIF- 8 membrane layer, ${ }^{36}$ the ZIF-8 membranes were attracted and anchored onto the support surface for the facile synthesis of well-intergrown ZIF-8 membranes, which is helpful for reducing the defect density and thus enhancing the separation selectivity. Further, compared with the literature data of $\mathrm{H}_{2}$ permeances of ZIF-8 membranes (Table 1) and other MOF-zeolite membranes (Table $\mathrm{S} 3 \dagger)$, the ZIF-8 membrane developed in this study shows a much higher $\mathrm{H}_{2}$ permeance. The obtained high $\mathrm{H}_{2}$ permeance of the ZIF-8 membrane is attributed to the high void volume of the SSN, which is helpful for reducing the flow resistance for gas transport. In addition, the ZIF-8 membrane prepared on a PDAfunctionalized SSN also showed high thermal stability (Fig. 6), and can keep its high $\mathrm{H}_{2}$ permselectivity when the $\mathrm{H}_{2}$ partial pressure increases from 0.5 to 1.5 bar (Fig. S4†).

\section{Conclusions}

In conclusion, we report a facile and universal seeding-free method for growing dense ZIF-8 membranes on thin and macroporous stainless-steel-nets, and the enhancing of their permeances by using an attachment chemistry based on polydopamine, a polymer inspired by marine mussels, for adhesion to surfaces. Attributed to the amazing adhesive ability of PDA, the ZIF-8 membranes are attracted and anchored onto the support surfaces for the formation of well-intergrown and highly selective ZIF-8 membranes. For binary mixtures at $100{ }^{\circ} \mathrm{C}$ and 1 bar, the mixture separation factors of $\mathrm{H}_{2}-\mathrm{CO}_{2}, \mathrm{H}_{2}-\mathrm{N}_{2}, \mathrm{H}_{2}-$ $\mathrm{CH}_{4}$ and $\mathrm{H}_{2}-\mathrm{C}_{3} \mathrm{H}_{8}$, were found to be 8.1, 15.0, 23.2 and 329.7, respectively, which by far exceed the corresponding Knudsen coefficients. The ZIF-8 membranes also displayed high permeances, with the $\mathrm{H}_{2}$ permeance higher than $2.1 \times 10^{-5} \mathrm{~mol}$ $\mathrm{m}^{-2} \mathrm{~s}^{-1} \mathrm{~Pa}^{-1}$, which by far exceed those of the as-reported ZIF-8 membranes, due to the high void volume of the SSNs. Further, the PDA functionalization also supports the formation of zeolite LTA growing on the inexpensive stainless-steel-nets.

\section{Acknowledgements}

Financial support from the National Natural Science Foundation of China (Grant no. 21276262), the Chinese Academy of Science Visiting Professorship for Senior International Scientists (Grant no. 2013T1G0047), and the Starting Research Fund of Team Talent from NIMTE (Grant no. Y20808A05) is acknowledged. The authors thank Mr H. Chen for help with FESEM measurements.

\section{References}

1 H. Li, M. Eddaoudi, M. O'Keeffe and O. M. Yaghi, Nature, 1999, 402, 276.

2 J. S. Seo, D. Whang, H. Lee, S. I. Jun, J. Oh, Y. J. Jeon and K. Kim, Nature, 2000, 404, 982.
3 L. J. Murray, M. Dincâ and J. R. Long, Chem. Soc. Rev., 2009, 38, 1294.

4 O. M. Yaghi, M. O'Keeffe, N. W. Ockwig, H. K. Chae, M. Eddaoudi and J. Kim, Nature, 2003, 423, 705.

5 J. R. Li, R. J. Kuppler and H. C. Zhou, Chem. Soc. Rev., 2009, 38, 1477.

6 S. Hermes, F. Schröder, R. Chelmowski, C. Wöll and R. A. Fischer, J. Am. Chem. Soc., 2005, 127, 13744.

7 E. Biemmi, C. Scherb and T. Bein, J. Am. Chem. Soc., 2007, 129, 8054.

8 R. Ranjan and M. Tsapatsis, Chem. Mater., 2009, 21, 4920.

9 G. Lu, O. K. Farha, W. Zhang, F. Huo and J. T. Hupp, Adv. Mater., 2012, 24, 3970.

10 Y. Yoo, Z. Lai and H.-K. Jeong, Microporous Mesoporous Mater., 2009, 123, 100.

11 Y. Yoo, V. Varela-Guerrero and H.-K. Jeong, Langmuir, 2011, 27, 2652.

12 S. Aguado, C. H. Nicolas, V. Moizan-Baslé, C. Nieto, H. Amrouche, N. Bats, N. Audebrandd and D. Farrusseng, New J. Chem., 2011, 35, 41.

13 K. S. Park, Z. Ni, A. P. Côté, J. Y. Choi, R. Huang, F. J. UribeRomo, H. K. Chae, M. O'Keeffe and O. M. Yaghi, Proc. Natl. Acad. Sci. U.S.A., 2006, 103, 10186.

14 Y. Li, F. Liang, H. Bux, A. Feldhoff, W. Yang and J. Caro, Angew. Chem., Int. Ed., 2010, 49, 548.

15 S. R. Venna and M. A. Carreon, J. Am. Chem. Soc., 2010, 132, 76.

16 H. Bux, F. Liang, Y. Li, J. Cravillon, M. Wiebcke and J. Caro, J. Am. Chem. Soc., 2009, 131, 16000.

17 M. C. McCarthy, V. Varela-Guerrero, G. V. Barnett and H.-K. Jeong, Langmuir, 2010, 26, 14636.

18 H. T. Kwon and H.-K. Jeong, J. Am. Chem. Soc., 2013, 135, 10763.

19 G. Xu, J. Yao, K. Wang, L. He, P. A. Webley, C. Chen and H. Wang, J. Membr. Sci., 2011, 385-386, 187.

20 Y. Pan and Z. Lai, Chem. Commun., 2011, 47, 10275.

21 Y. Pan, B. Wang and Z. Lai, J. Membr. Sci., 2012, 421-422, 292.

22 J. Yao, D. Dong, D. Li, L. He, G. Xu and H. Wang, Chem. Commun., 2011, 47, 2559.

23 E. Barankova, N. Pradeep and K.-V. Peinemann, Chem. Commun., 2013, 49, 9419.

24 K. Huang, Z. Dong, Q. Li and W. Jin, Chem. Commun., 2013, 49, 10326.

25 Z. Xie, J. Yang, J. Wang, J. Bai, H. Yin, B. Yuan, Ji. Lu, Y. Zhang, L. Zhou and C. Duan, Chem. Commun., 2012, 48, 5977.

26 A. Huang, H. Bux, F. Steinbach and J. Caro, Angew. Chem., Int. Ed., 2010, 49, 4958.

27 Y. Liu, E. Hu, E. A. Khan and Z. Lai, J. Membr. Sci., 2010, 353, 36.

28 X. Dong and Y. S. Li, Chem. Commun., 2013, 49, 1196.

29 A. Huang, W. Dou and J. Caro, J. Am. Chem. Soc., 2010, 132, 15562.

30 A. Huang, N. Wang, K. Kong and J. Caro, Angew. Chem., Int. Ed., 2012, 51, 10551. 
31 A. J. Brown, J. R. Johnson, M. E. Lydon, W. J. Koros, C. W. Jones and S. Nair, Angew. Chem., Int. Ed., 2012, 51, 10615.

32 A. Huang, Y. Chen, N. Wang, Z. Hu, J. Jiang and J. Caro, Chem. Commun., 2012, 48, 10981.

33 O. Shekhaha and M. Eddaoudi, Chem. Commun., 2013, 49, 10079.
34 Q. Liu, N. Wang, J. Caro and A. Huang, J. Am. Chem. Soc., 2013, 135, 17679.

35 X. Yin, G. Zhu, W. Yang, Y. Li, G. Zhu, R. Xu, J. Sun, S. Qiu and R. Xu, Adv. Mater., 2005, 17, 2006.

36 J. H. Waite and M. L. Tanzer, Science, 1981, 212, 1038.

37 H. Lee, S. M. Dellatore, W. M. Miller and P. B. Messersmith, Science, 2007, 318, 426. 